SAND92-2521

Unlimited Release

Printed June 1993
Distribution

Category UC-900

\title{
How to Apply the IEEE Standards to Software Testing
}

\author{
Jan Klamerus \\ Joan Weeks \\ Information Technology Department \\ Sandia National Laboratories \\ Albuquerque, NM 87185
}

\begin{abstract}
Testing is an important part of the software application development process. To achieve quality software deliverables and to avoid costly redevelopment of program code or repair of bad data, testing must be performed throughout the software development life cycle. This paper will discuss a software engineering process to produce a software test plan based upon the "IEEE (Institute of Electrical and Electronics Engineers) Software Engineering Standards Collection" guidelines and corporate guidelines. Demonstrated examples of the software testing process involving interactive graphical user interface software and standard ASCII forms-based text are provided. Sandia National Laboratories has a Software Quality Assurance Department which provides corporate guidelines, in addition to recommending the use of IEEE processes.

Both corporate guidelines and a specific subset of the IEEE guidelines were applied to the software development projects discussed herein. The rationale for applying a specific subset of the IEEE guidelines for each of the software development projects will be given. The development of the test procedures in the INGRESMINDOWS 4GL environment (graphical user interface) as well as in the INGRES/ABF environment (Applications-By-Forms, ASCII Text) will be presented and contrasted. The documentation of the testing process and results are explained.
\end{abstract}




\section{Table of Contents}

1. Introduction $\ldots \ldots \ldots \ldots \ldots \ldots \ldots \ldots \ldots \ldots \ldots \ldots \ldots \ldots \ldots \ldots$

2. Documentation Needed $\ldots \ldots \ldots \ldots \ldots \ldots \ldots \ldots \ldots \ldots \ldots . \ldots \ldots$

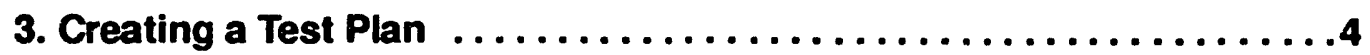

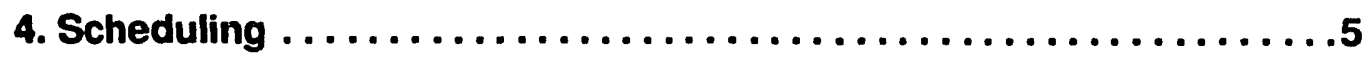

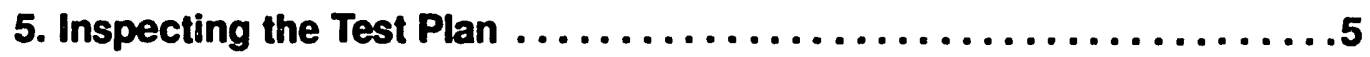

6. Developing Test Procedures $\ldots \ldots \ldots \ldots \ldots \ldots \ldots \ldots \ldots \ldots \ldots$

7. Documenting the Results $\ldots \ldots \ldots \ldots \ldots \ldots \ldots \ldots \ldots \ldots \ldots$

8. Evaluating the Testing $\ldots \ldots \ldots \ldots \ldots \ldots \ldots \ldots \ldots \ldots$

9. Summary $\ldots \ldots \ldots \ldots \ldots \ldots \ldots \ldots \ldots \ldots \ldots \ldots \ldots \ldots \ldots \ldots$

Appendix A. ABF (ASCll forms-based text) Test Plan . . . . . . . . . 10

Appendix B. WINDOWS4GL Test Plan $\ldots \ldots \ldots \ldots \ldots \ldots \ldots \ldots$

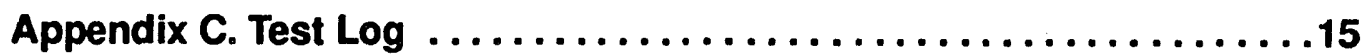

Appendix D. Discrepancy Report $\ldots \ldots \ldots \ldots \ldots \ldots \ldots \ldots \ldots \ldots$ 


\section{Introduction}

The purpose of testing is to verify software requirements, and to expose as many errors in the application as possible. Testing performed throughout the software development process avoids costly redevelopment of program code. If an application is released into production without being tested, it could be costly and time consuming to the company and the development team. These problems can be avoided if testing has been performed throughout the development process. Testing should always be planned and scheduled for every software database application new or revised.

Discussed within is a software engineering process to produce a software test plan based upon the "IEEE (Institute of Electrical and Electronics Engineers) Software Engineering Standards Collection". Examples of graphical user interface software and Standard ASCII forms-based programming environments are provided. The IEEE guidelines can provide a broad structure for most software development projects.

This paper discusses:

- Documentation needed to effectively develop the test plan and test procedures

- Creating a test plan and the rational for choosing a specific subset of the IEEE guidelines

- Coordinating the testing schedule

- Inspecting the test plan

- Developing test procedures

- Documenting the results

- Evaluating the testing

\section{Documentation Needed}

Software documentation is the key to successful testing. Without the proper documentation software testing is like "taking a shot in the dark", it is not possible to gauge how accurate it is. To effectively test one must know the range of acceptable values, and what is and what is not supposed to occur.

The documents that contain this information are the Software Requirements Document and the Design Document. Documents such as screen prints, binder 
diagrams, menu descriptions, and flow descriptions can also be used as sources of information for the testing. The relationship between a developer and tester depends on how complete these documents are. If the documents are ill defined or there are no documents this can set an antagonistic tone between the testers and developers.

From these documents the information that should be obtained is:

- inputs and outputs

- boundaries of the system

- security features

- screen layouts

- screen options that should be available (add, delete, modify, etc...)

- field sizes

- valid field formats (char, integer, decimal, etc...)

- platforms (it may be necessary to test multiple platforms)

- performance requirements

After obtaining the above information a test plan and test procedures can be developed.

\section{Creating a Test Plan}

The IEEE guidelines can be used as a template for development projects. The IEEE guidelines refer to all areas of the application that need to be tested. These may be used to create a rigorous test plan for a large project or a simple test plan for smaller projects. The IEEE guidelines provide a guide to perform thorough testing. These guidelines are general enough to be used for testing any type of system and ensuring that it has been rigorously tested. An inspection of the test plan will help to ensure all of the applicable areas are being tested.

In order to create a test plai, first list all the IEEE guidelines headings in your test plan, this assures that all requirements will be covered. Also create a heading "Items Not to be Tested" in the test plan. If a guideline heading is not applicable to the software development project include it under the heading called "ltems Not to 
be Tested", to show that each item has been consider for testing. The Software Requirements Document contains information for the scope of the test plan. The Software Design Document contains information for the detail of the test plan, and also describes what needs to be tested and how the requirements have been implemented. The headings should be put in terms closely related to the software requirements and design documents you are working with. If it is uncertain whether the heading pertains to the test plan keep it in the test plan as a reminder to question it at a review or inspection. The Test Plan is prepared on a baseline application. This means that no one should be making changes to the application while writing the test plan or performing the procedures. Once a basic software test plan has been created, this test plan can be used as a template for other development projects. See Appendix A \& B for examples of two different test plan table of contents'.

\section{Scheduling}

In order for the testing to be performed smoothly, part of the test plan should include a schedule of tasks and assignments. A simple GANTT chart with tasks, and who is responsible for performing the task is sufficient. The schedule should include dates when the testing will be performed, when the test plan will be inspected and approved, and when the test procedures will be inspected and approved. In addition, personnel must be scheduled for the testing.

A Test Team should be created that includes a Test Director, at least one Test Analyst, and a Quality Assurance person. The Test Director should be responsible for scheduling the time, date, place to perform the testing, and the equipment to use for the testing. The Test Director also, makes sure everyone on the test team has access to the application being tested.

\section{Inspecting the Test Plan}

Once the test plan has been written, a test inspection should be arranged. The personnel selected to inspect the test plan should include: the test team, and someone from the development team. The inspection team should consist of $4-6$ people. The test plan is inspected for accuracy as well as reasonable ability to meet the dates and requirements specified. The Test Director assigns the following roles to the participants: moderator, reader, and recorder from among the people selected for the inspection. The reader should not be the creator of the test plan, because the creator may read in what they meant to write instead of what is printed. The inspection meeting is to identify the errors and not to fix them, it should not last more than 11/2 hours. The inspection standard format that is covered is given by Sandia National Laboratories Software QA Organization, and it is possible that it is base on the Software Engineering Institute format. 
A memo is sent out to inform these people of the inspection. The memo contains this information:

- what will be inspected.

- the location, date, and time of the inspection.

- duties each person will perform at the inspection.

The test plan is attached to the memo so everyone has a copy of it to review before the inspection. The memo and test plan should be sent out one week before the inspection to give everyone a chance to review it and make comments on it prior to the inspection meeting.

At the beginning of the test plan inspection, the moderator inquires how much time each participant spent reviewing the test plan. This is to ensure that everyone is prepared. If the participants are not prepared, the meeting should be cancelled and rescheduled. During the test plan inspection, the test plan is read and errors are identified. The recorder notes all errors. At the end of the inspection, it should be determined if another inspection meeting is necessary or whether to just make the changes on the test plan and distribute it for approval from each of the members of the inspection group. Determining if another inspection is needed for the test plan, depends upon the quantity and quality of discrepancies found. If only a few, minor discrepancies are found, then it is possible to make the changes and distribute the test plan for approval. Otherwise, a reinspection is necessary. For a reinspection, the changes are made and the same steps are followed as before. By using the IEEE guidelines to create the test plan, the discrepancies are minimized. These same inspection steps should be followed for the Test Procedures.

After the Test Plan is finalized it is put into Configuration Management. This is to control changes made to the Test Plan. Configuration Management is a change control system in which only the change control team can make changes to the Test Plan. This is helpful so that anyone using the document can be assured that they have the current version.

\section{Developing Test Procedures}

Test Procedures should be written so that anyone can perform the testing. Including someone who has never worked with the application before. Each member of the test team should follow the instructions in the test procedures stepby-step. The more explicit the test procedures are, the easier they are to follow. 
The test procedures may be used again for retesting of the system after errors have been corrected.

The test procedures should be written so that they check each option using real data (positive testing), and then using false data (negative testing) to check the boundaries of the system such as error messages, or if the system accepts invalid data.

Once the test procedures have been written, a test inspection should be arranged. Follow the same inspection steps as performed for the test plan. Once the test procedures have been inspected and approved then execute them. Testing should be done against a baseline application. No updates will be made to the application until the testing is completed from start to finish. The testing will not be interrupted unless a major incident affects the steps of the procedure. A major incident is one that creates a testing impasse or affects the remaining steps of the procedure. The Quality Assurance person can perform or observe the testing to ensure that the procedures cover all the options.

\section{Documenting the Results}

The Test Logs, Appendix $C$, are used for documenting the test results. The Test Log contains the following information: the Test Analyst, the date, test procedures, frame name, minor or major, discrepancy number, and comment. As the Test Analyst performs the test procedures, incidents are recorded on the Test Logs. The Test Analyst fills in the test procedure number, the test step being executed, whether it is a minor or major incident, and briefly describes the incident that occurred. At the end of the testing, all of the Test Logs are compiled and each incident is assigned a Discrepancy report.

A Discrepancy Report, Appendix D, is filled out about each incident. The Discrepancy Report contains the following information: an ID number, the originator, the assigned to, the frame name, the description field, and the resolution. At the end of the testing session, the Discrepancy Reports are given to the project leader or development leader to prioritize the corrections in the code. The project leader assigns a Discrepancy Report to a developer to resolve. The developer completes the bottom half of the Discrepancy Report by stating the resolution to the problem, and signing the Discrepancy Report. After the corrections are made, the Discrepancy Reports are returned to the Test Director. Another test is performed to ensure that the corrections made did not create other problems.

After all testing is completed for the project the documentation is compiled and delivered to the customer. The customer will receive a copy of the test plan, which includes the Test Procedures, Test Summary Report, Test Logs, and Discrepancy Reports. 


\section{Evaluating the Testing}

It is important to evaluate the testing at the end of a project to see how it could have been performed more efficiently. Questions to ask when evaluating the testing are:

- Did the test procedures cover all of the options?

- After each test, were less incidents reported?

- How long did it take the test analysts to perform the testing, and did their performance increase after each test?

- Did the test analysts understand the test procedures and follow them correctly?

These types of questions provide important feedback and can help the Test Director improve the testing process for the next project. This feedback gives the Test Director information on how effective the testing was performed.

\section{Summary}

The purpose of software testing is working as a team member with the developers to identify errors in the code. The guidelines provided by IEEE are general enough to be used for testing any type of system and ensuring it has been rigorously tested. The Software Requirements and Design documents are necessary to create a test plan and test procedures. These documents set the tone of the relationship between the tester and developer. After obtaining these documents, create the test plan using the IEEE procedures that apply to your application. Depending on the Software Requirements and the type of system being developed (ABF or Windows 4GL) there will be differences in the test plans and procedures. The Test Director needs to get involved from the beginning to the end of the project. The Test Director is responsible for scheduling the testing, the personnel, and the equipment.

After a rough draft of the test plan has been developed, arrange an inspection meeting to inspect the test plan for any errors or important data that may have been overlooked. After the test plan has been inspected the final version of the test plan is put into Configuration Management to deliver to the customer at the end of the project. The test plan may be used as a template for future test plans on other projects. After the test plan has been finalized, the test procedures can be written. The more explicit the test procedures are the easier they are to follow. Once the test procedures are written, arrange an inspection of the test procedures to ensure that all of the options are covered, then execute the test procedures. The results should be documented using the Test Logs and Discrepancy Reports. 
After the errors have been corrected it is necessary to retest the system, to ensure that the corrections did not create other problems. When the testing is completed, provide the test team with a questionnaire to evaluate the testing. The evaluation of the testing should be used to improve the testing process for the next project.

Once the testing has been completed and the results have been documented. The documentacion needs to be signed off and delivered to the customer. The documentation given to the customer includes the test plan, test procedures, test summary report, test logs, and discrepancy reports. 


\section{Appendix A. ABF (ASCIl forms-based text) Test Plan}




\section{Software Test Plan \\ Management Integration and \\ Implementation Project}

\section{Contents}

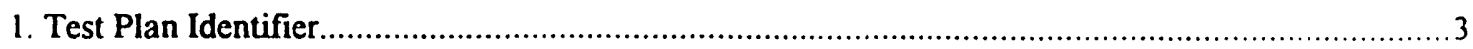

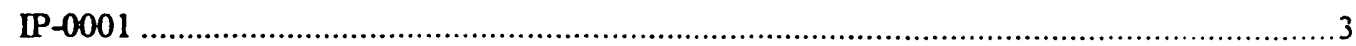

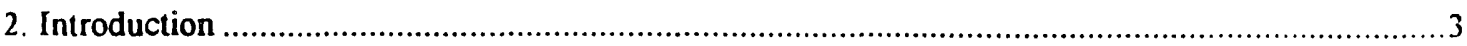

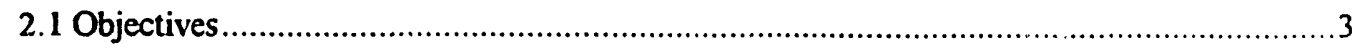

2.2 Scope

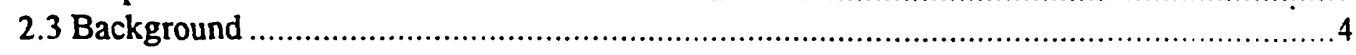

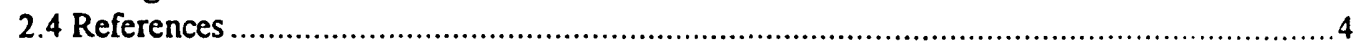

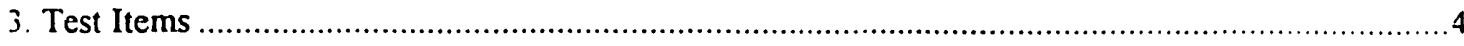

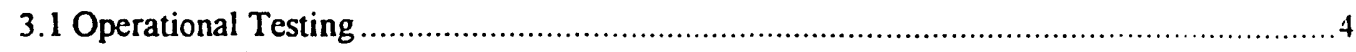

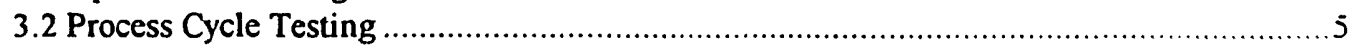

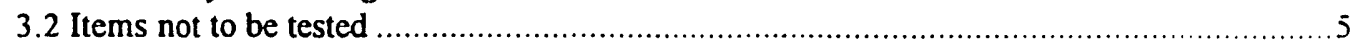

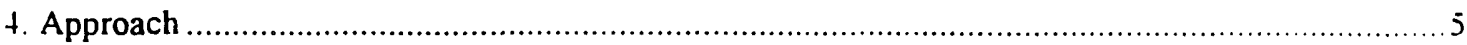

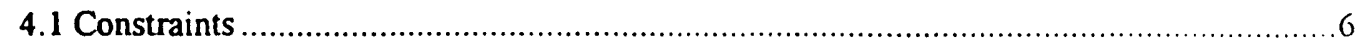

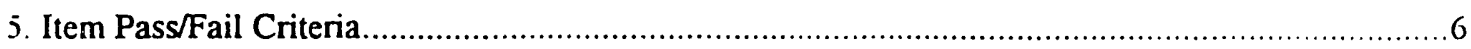

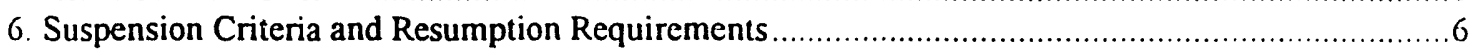

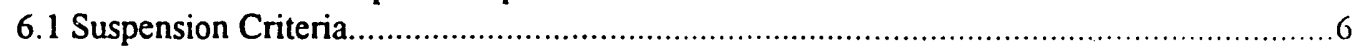

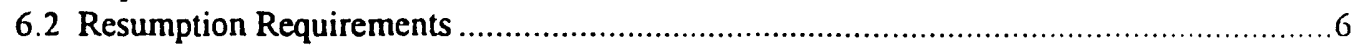

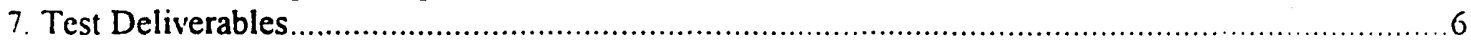

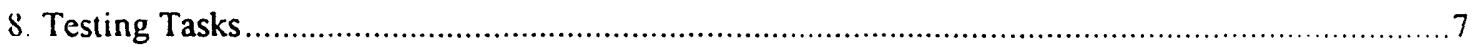

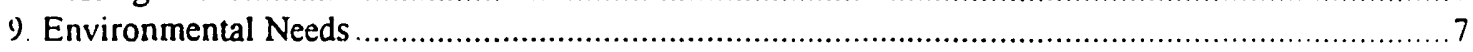

9.1 Hardware

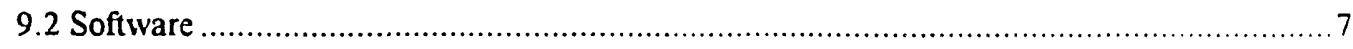

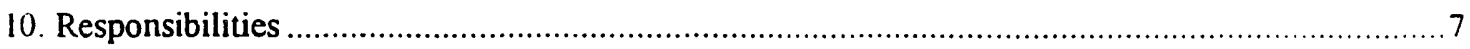

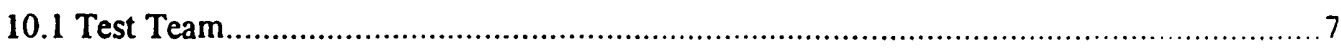

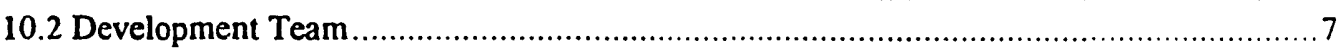

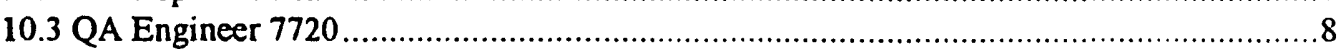

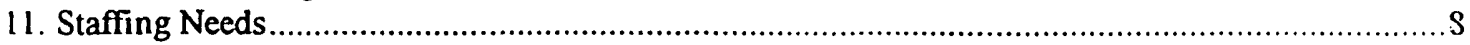

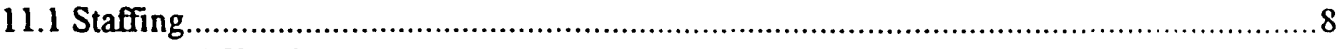

12. Schedule

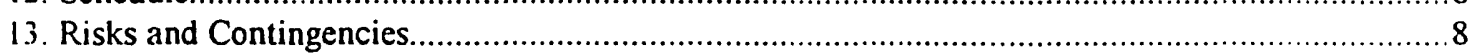

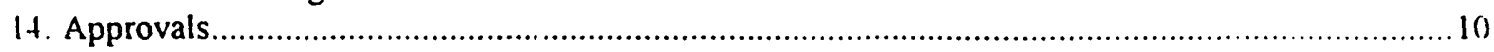

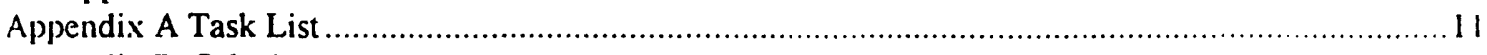

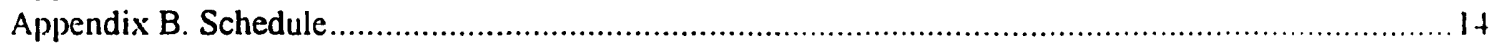

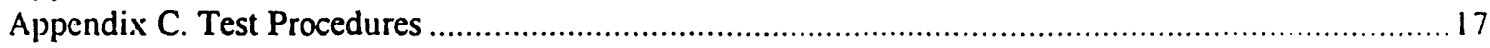

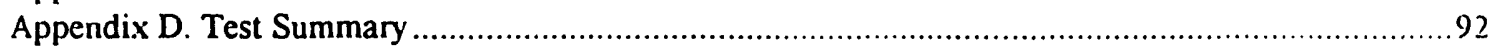

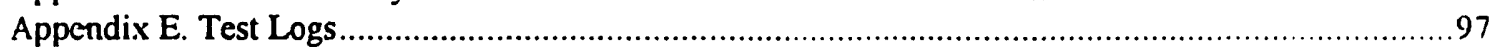

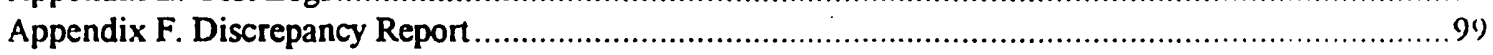

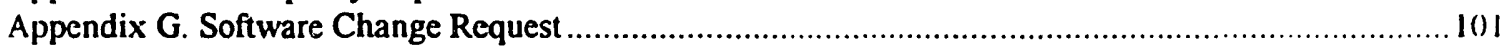

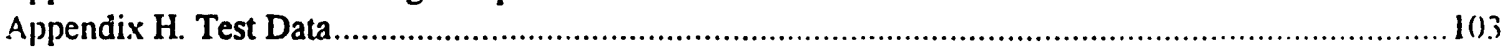

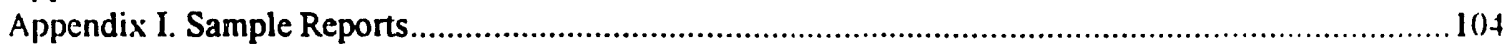


Appendix B. WINDOWS4GL Test Plan 
Stockpile Dismantlement Software Test Plan - Phase II

Table of Contents

1. Test Plan Identifier. ..................... 4

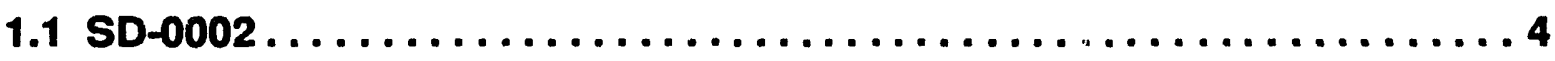

2. Introduction ........................

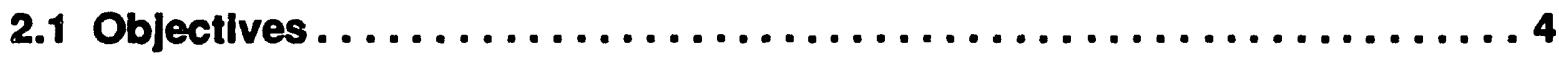

2.2 Scope.........................................4

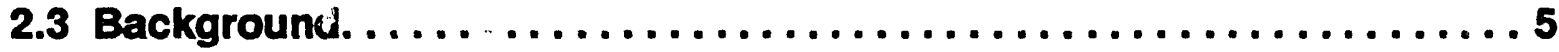

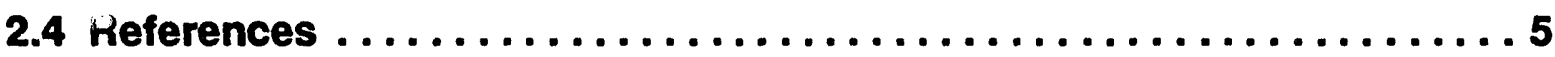

3. Test Items . . . . . . . . . . . . . . . . . . . . 6

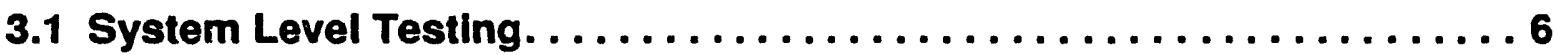

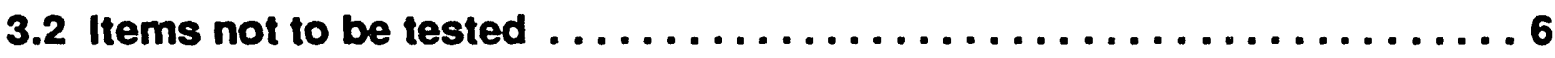

4. Approach $\ldots \ldots \ldots \ldots \ldots \ldots \ldots \ldots \ldots \ldots \ldots \ldots \ldots \ldots 6$

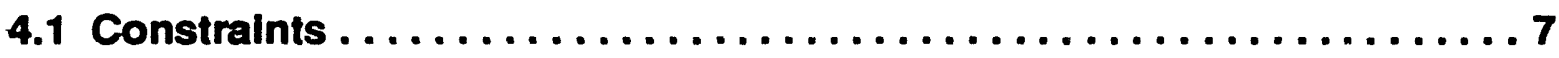

5. Item Pass/Fail Criteria . . . . . . . . . . . . . . . . 7

6. Suspension Criteria and Resumption Requirements....... 8

6.1 Suspension Criteria ............................. 8

€.2 Resumption Requirements ........................ 8

7. Test Deliverables . . . . . . . . . . . . . . . . . . 8

7.1 Test Documentation: . . . . . . . . . . . . . . . . . . . . . 8

8. Testing Tasks.........................

9. Environmental Needs ..................... 9

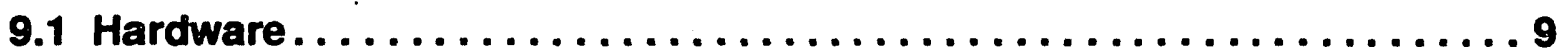

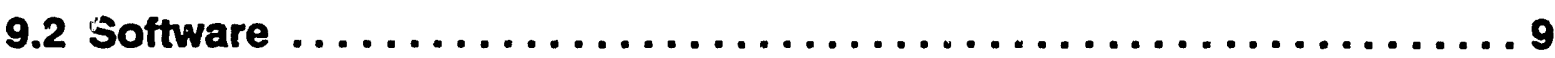

10. Responsibilities ....................... 9

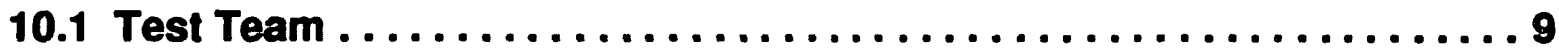

10.2 Development Team................................ 9

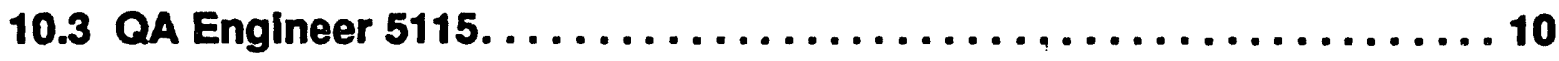

11. Staffing Needs ....................... 10

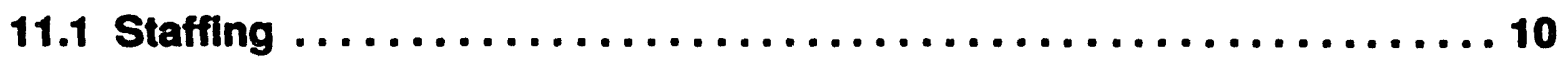

11.1.1 Test Team.$\ldots \ldots \ldots \ldots \ldots \ldots \ldots \ldots \ldots \ldots \ldots \ldots \ldots \ldots \ldots \ldots$ 
12. Schedule. . . . . . . . . . . . . . . . . . . 10

13. Risks and Contingencies $\ldots \ldots \ldots \ldots \ldots \ldots \ldots \ldots \ldots \ldots$

Appendix A. Task List . . . . . . . . . . . . . . . . . 12

Appendix B. Test Procedures. . . . . . . . . . . . . . 15

Appendix C. Test Summary Report . . . . . . . . . . . . 91

Appendix D. Test Logs . . . . . . . . . . . . . . . . . . .97

Appendix E. Discrepancy Report ...................99 
Appendix C. Test Log 


\section{Test Log}

Tester:

Date:

Function Title:

\begin{tabular}{|c|c|c|c|c|}
\hline $\begin{array}{l}\text { Test } \\
\text { Case \# }\end{array}$ & Frame Name & $\begin{array}{l}\text { Minor/ } \\
\text { Major/ } \\
\text { None }\end{array}$ & $\begin{array}{l}\text { Discrepancy } \\
\#\end{array}$ & Comment \\
\hline & & & & \\
\hline & & & & \\
\hline & & & & \\
\hline & & & & \\
\hline & & & & \\
\hline & & & & \\
\hline & & & & \\
\hline.. & & & & \\
\hline & & & & \\
\hline & & & & \\
\hline & & & & \\
\hline & & & & \\
\hline & & & & \\
\hline & & & & \\
\hline & & & & \\
\hline & & & & \\
\hline & $\therefore$ & & & \\
\hline & & & & \\
\hline & & & & \\
\hline & & & & \\
\hline & & & & \\
\hline
\end{tabular}




\section{Appendix D. Discrepancy Report}




\section{Discrepancy Report}

ID \#:

Originator:

Date Noted:

Assigned to:

Date Started:

Date Completed:

Frame Name:

Description:

Resolution:

Time Spent:

Developer 
Distribution:

$\begin{array}{llr}2800 & \text { J.F. Jones, Jr. (Acting) } & (1) \\ 2863 & \text { G.E.Rivord } & (1) \\ 2863 & \text { D.S. Eaton } & (1) \\ 2863 & \text { M.M. Hess } & (1) \\ 2863 & \text { E.J. Klamerus } & (6) \\ 2863 & \text { J.C. Weeks } & (6) \\ 7141 & \text { Technical Library } & (5) \\ 7151 & \text { Technical Publications } & (1) \\ 7613-2 & \text { Document Processing for DOE/OSTI } & (10) \\ 8523 & \text { Central Technical Files }\end{array}$



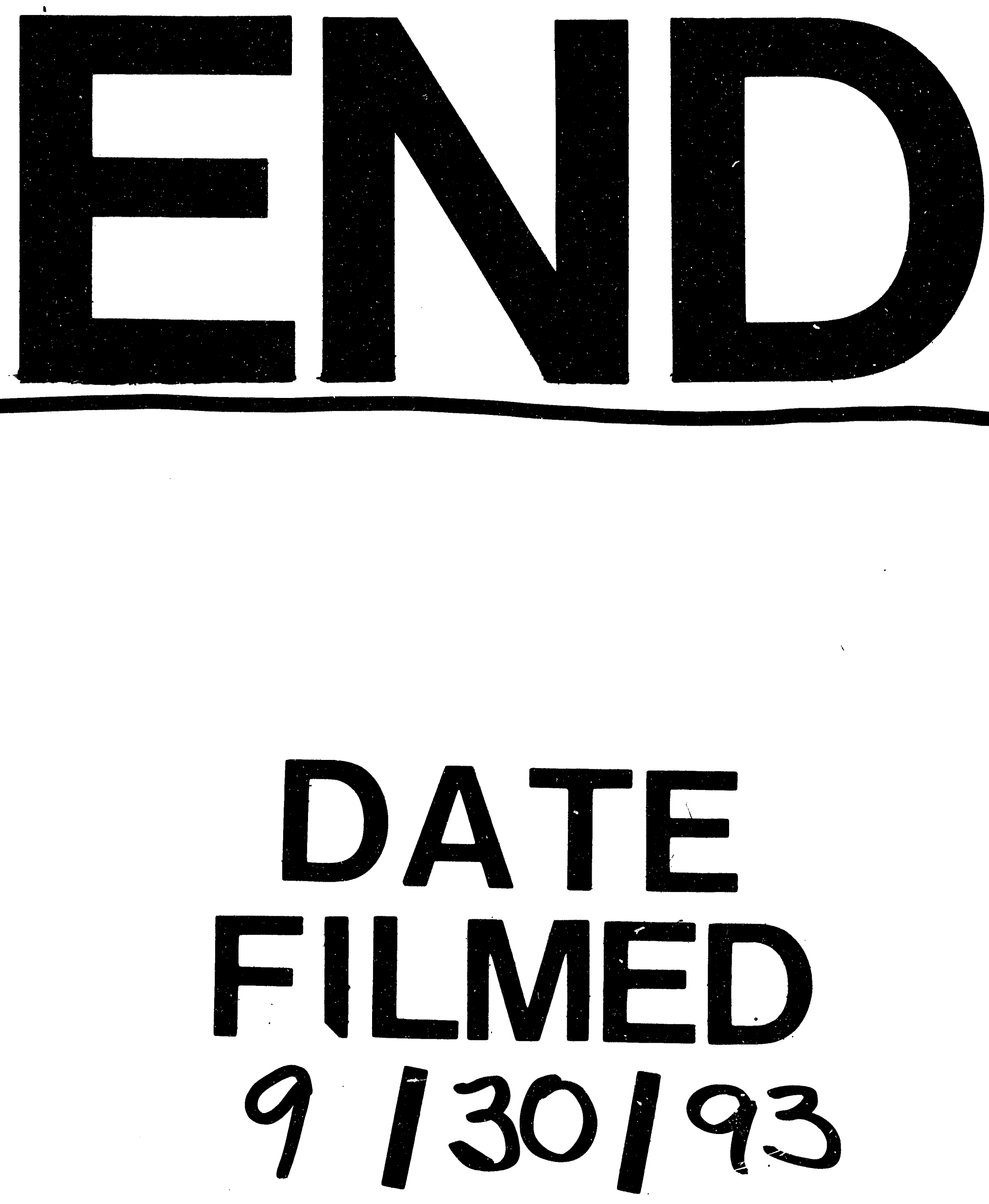

I 
